\title{
Fungitoxicidade, atividade elicitora de fitoalexinas e proteção de alface em sistema de cultivo orgânico contra Sclerotinia sclerotiorum pelo extrato de gengibre
}

\author{
Edvirgem Rodrigues ${ }^{1}$, Kátia Regina Freitas Schwan-Estrada ${ }^{1,3}$, Ana Cristina G. Fiori-Tutida ${ }^{1}$, \\ José Renato Stangarlin ${ }^{2,3}$, Maria Eugênia Silva Cruz ${ }^{1}$
}

${ }^{1}$ Departamento de Agronomia, Pós-graduação, Universidade Estadual de Maringá (UEM), Av. Colombo 5790, CEP 87020-900, Maringá, PR, email: schwan@wnet.com.br. Trabalho referente à Dissertação de Mestrado do primeiro autor; ${ }^{2}$ Centro de Ciências Agrárias, Universidade Estadual do Oeste do Paraná (UNIOESTE), Rua Pernambuco 1777, Caixa Postal 1008, CEP 85960-000, Marechal Cândido Rondon, PR; ${ }^{3}$ Bolsistas de Produtividade em Pesquisa do CNPq. Autor para correspondência: Kátia R.F. Schwan-Estrada.

Data de chegada: 18/08/2005. Aceito para publicação em: 20/06/2006.

\section{RESUMO}

Rodrigues, E.; Schwan-Estrada, K.R.F.; Fiori-Tutida, A.C.G.; Stangarlin, J.R.; Cruz, M.E.S. Fungitoxicidade, atividade elicitora de fitoalexinas e proteção de alface em sistema de cultivo orgânico contra Sclerotinia sclerotiorum pelo extrato de gengibre. Summa Phytopathologica, v.33, n.2, p.124-128, 2007.

O patógeno Sclerotinia sclerotiorum é um fungo que sobrevive no solo e causa a doença conhecida como mofo branco ou podridão de esclerotínia na cultura da alface (Lactuca sativa) e outras culturas. A doença é considerada de difícil controle, uma vez que o fungo é muito agressivo e produzem estruturas de resistência, os escleródios. Na busca de novos métodos de controle de doenças, os extratos de plantas com propriedades terapêuticas surgem como opção. Neste trabalho avaliouse o efeito do extrato bruto aquoso (EBA) de gengibre (Zingiber officinalis) nas concentrações de $1,5,10,15,20$ e $25 \%$ sobre o crescimento micelial e produção de escleródios de S. sclerotiorum, in vitro. Também foi verificada a eficiência do gengibre na proteção de plantas de alface cultivadas organicamente e inoculadas com o patógeno. Além da incidência da doença, foi analisado o rendimento da cultura e a atividade de peroxidase nos tecidos da planta. Água e o indutor de resistência acibenzolar-S-metil foram utilizados como tratamentos controle. Adicionalmente, a capacidade elicitora do EBA de gengibre em proporcionar o acúmulo das fitoalexinas deoxiantocianidina e gliceolina foi avaliada em bioensaios com sorgo e soja, respectivamente. Os resultados indicaram a atividade antimicrobiana dos EBA de gengibre, com inibição do crescimento micelial e da produção de escleródios. Na cultura da alface, verificou-se que a aplicação de massa de gengibre na base da planta aumentou a atividade da enzima peroxidase e reduziu a incidência da doença. A presença de compostos elicitores no EBA de gengibre foi observada pela indução da produção de fitoalexinas em sorgo e soja, que ocorreu de maneira dosedependente. Estes resultados indicam o potencial de Z. officinalis para o controle de S. sclerotiorum em alface, o qual pode ocorrer tanto por atividade antimicrobiana direta quanto pela ativação de mecanismos de defesa das plantas.

Palavras-chave adicionais: extrato de plantas, controle alternativo de doenças, indução de resistência.

\begin{abstract}
Rodrigues, E.; Schwan-Estrada, K.R.F.; Fiori-Tutida, A.C.G.; Stangarlin, J.R.; Cruz, M.E.S. Fungitoxicity, phytoalexins elicitor activity and protection of grown against Sclerotinia sclerotiorum by ginger extract. Summa Phytopathologica, v.33, n.2, p.124-128, 2007.

Sclerotinia sclerotiorum is a soilborne fungus and causes white mold, sclerotinia cottony rot in lettuce (Lactuca sativa) and other crops. The control of this disease is very difficult, since that fungus produces resistance structures, the sclerodia. In the search of new methods for disease control, the plant extracts with therapeutical properties arise as a new option. The effect of aqueous crude extract (ACE) of ginger (Zingiber officinalis) was evaluated in vitro at concentrations of $1,5,10$, 15,20 and $25 \%$ on S. sclerotiorum mycelial growth and sclerodia production. The efficiency of ginger on the production of lettuce plants was also verified in plants and inoculated with the pathogen. Disease incidence, crop yield and peroxidase activity were analyzed in plant tissue. Water and the resistance inducer agent acibenzolar-S-methyl were

used as control. Additionally, the ability of ACE in inducing accumulation of phytoalexins 3-deoxyanthocyanidin and glyceollin was evaluated in sorghum and soybean bioassays, respectively. The results showed the antimicrobial activity of ginger on the inhibition of mycelial growth and sclerodia production. In the lettuce crop, it was observed that the application of ginger mass on the soil close to plants basis increased of peroxidase activity and reduced disease incidence. The presence of elicitor compounds in the ACE was detected by the production of phytoalexins in sorghum and soybean, with dosedependent responses. These results showed the potential of $Z$. officinalis on the control of $S$. sclerotiorum in lettuce that can occur by antimicrobial activity and defense mechanisms induction.
\end{abstract}

Additional keywords: plant extract, alternative control of diseases, resistance induction. 
A alface (Lactuca sativa L.) está entre as dez hortaliças mais apreciadas in natura no Brasil (8). Entretanto, esta cultura apresenta várias doenças dentre as quais destaca-se o mofo branco ou podridão de esclerotínia causada pelo fungo Sclerotinia sclerotiorum (Lib.) De Bary, um patógeno que sobrevive no solo e que infecta mais de 360 espécies de plantas (2). Este patógeno pode atacar a planta em qualquer estádio de desenvolvimento, principalmente próxima à colheita $\mathrm{e}$ produz estruturas de resistência denominadas escleródios, que tornam a doença de difícil controle em função do longo período de permanência destas no solo (20).

Com o avanço do sistema de produção orgânica de plantas, há interesse na busca de novas práticas agrícolas que substituam os métodos convencionais de controle de doenças. Em vista disso, atenção tem sido voltada para a utilização de métodos alternativos aos fungicidas tradicionais, que sejam eficientes com o mínimo de impacto ambiental e perigo aos consumidores (23). Compostos secundários presentes em plantas medicinais podem desempenhar funções importantes em interações planta-patógeno, através da ação antimicrobiana direta, ou ativando mecanismos de defesa das plantas que venham a ser tratada com estes compostos (24). Pandey et al. (19) constataram inibição de $90 \%$ no crescimento micelial do fungo Helminthosporium sativum, quando se utilizou extrato de Allium sativum, Azadirachta indica, Lawsonia inermis e Matricaria chamomil. Bonaldo et al. (6) verificaram que os extratos aquosos de Eucalyptus citriodora autoclavado e não autoclavado induziram a síntese de fitoalexinas 3-deoxiantocianidinas e gliceolinas e apresentaram potencial para induzir resistência local em pepino contra Colletotrichum lagenarium. Há ainda vários outros exemplos como o controle da mancha marrom (Bipolaris sorokiniana) em trigo pelo extrato aquoso de Artemisia camphorata (cânfora) (14), do oídio (Oidium lycopersici) do tomateiro pelo óleo emulsionável de Azadirachta indica (nim) (9) e do tombamento e requeima (Rhizoctonia solani) de plântulas de feijão vagem pelo óleo essencial de Brassica rapa (mostarda) (11).

Kuhn et al.(17) estudaram o efeito de Curcuma longa (cúrcuma ou açafrão), planta da mesma família do gengibre, sobre Xanthomonas axonopodis pv. manihotis. In vitro, o extrato apresentou ação bactericida para concentrações que variaram de 10 a $20 \%$, dependendo da procedência dos rizomas. No entanto, in vivo, nas concentrações utilizadas, não houve efeito curativo em manivas de mandioca infectadas com o patógeno. Becker et al. (5) avaliaram o efeito da curcumina a $50 \mathrm{mg} . \mathrm{L}^{-1} \mathrm{e}$ verificaram que proporcionou o melhor resultado de peso total de sementes de soja em ensaio para controle de doenças de final de ciclo (Septoria glycines e Cercospora kikuchii) e oídio (Microsphaera diffusa) em condições de campo. Já Balbi-Peña (4) avaliou a curcumina e os extratos brutos de cúrcuma no controle da pinta preta do tomateiro e verificou que os níveis de controle da doença foram similares ao tratamento com fungicida cúprico, mas inferior ao fungicida sistêmico azoxistrobina, embora a maior porcentagem de frutos grandes tenha sido obtido com a aplicação de curcumina a $50 \mathrm{mg} . \mathrm{L}^{-1}$.

O gengibre, pertence à família Zingiberaceae e apresenta em seu rizoma princípios ativos considerados antimicrobianos como o gingerol, zingibereno dentre outros (1). Desta forma, o presente trabalho teve como objetivos verificar o efeito do extrato bruto aquoso de gengibre sobre o crescimento micelial e a produção de escleródios de Sclerotinia sclerotiorum, in vitro, bem como do uso do gengibre, em diferentes formas, na cultura da alface e sua relação entre o controle do patógeno e a indução de mecanismos de resistência (fitoalexinas e peroxidases).

\section{MATERIAL E MÉTODOS}

\section{Obtenção do extrato bruto aquoso de gengibre (EBA)}

Para obtenção do EBA, raízes de gengibre (500 g.L.-1) foram trituradas em liquidificador, filtrada em gaze e em papel de filtro Whatman $n^{\circ} 41$ obtendo-se o extrato líquido a $50 \%$. A partir deste, foram feitas diluições para obter-se concentrações de 1, 5, 10, 15, 20 e $25 \%$ sendo incorporado em meio BDA, seguido de autoclavagem utilizado para avaliar o crescimento micelial e produção de escleródios. O material retido no filtro Whatman $\mathrm{n}^{\circ} 41$ foi caracterizado como massa de gengibre (MG) e utilizado no experimento a campo.

\section{Isolamento do patógeno}

Os escleródios de S. sclerotiorum foram coletados em plantas de alface cultivadas em sistema orgânico. As estruturas foram transferidas para placas de Petri contendo meio BDA, sendo estas incubadas no escuro, a $25^{\circ} \mathrm{C}$. Após isolamento, as placas permaneceram sete dias em incubação, sendo em seguida conservadas em geladeira (placas matrizes).

\section{Inibição do crescimento micelial e produção de escleródios}

Um disco de $7 \mathrm{~mm}$ de diâmetro contendo micélio de S. sclerotiorum, com sete dias de cultivo, foi repicado para o centro de placas contendo as diferentes concentrações de gengibre incorporadas ao meio BDA e estas foram mantidas em BOD a $25^{\circ} \mathrm{C}$, no escuro. As avaliações foram realizadas através de medições diárias do diâmetro das colônias (média de duas medidas diametralmente opostas) e prosseguiram até o momento em que as colônias fúngicas atingiram 3/4 da superfície do meio de cultura (24). Após a avaliação do crescimento micelial, procedeu-se a contagem de escleródios por tratamento. O delineamento utilizado foi inteiramente casualizado, com sete tratamentos $(0,1,5$, $10,15,20$ e $25 \%$ ) e três repetições. No tratamento controle foi utilizado somente o meio BDA. O estudo do fator quantitativo (concentrações) foi realizado através de análise de regressão.

\section{Proteção de alface contra $S$. sclerotiorum}

$\mathrm{O}$ experimento foi conduzido em área de produção orgânica de hortaliças. Cada parcela foi composta por quatro linhas de alface com espaçamento de $0,3 \times 0,3 \mathrm{~m}$, utilizando-se as duas linhas centrais para as avaliações, com três repetições. A bordadura foi composta pelas linhas externas de cada parcela, além de uma planta do início e final de cada uma das linhas centrais, perfazendo dez plantas úteis de alface por parcela. Utilizou-se a cultivar de alface Tainá, e esta foi semeada em bandejas de poliestireno. As mudas foram transplantadas para os canteiros (parcela) quando tinham seis a oito folhas expandidas. Após o transplante, os canteiros foram cobertos com casca de arroz e de café e após 40 dias, deu-se início a aplicação dos tratamentos: (1) pulverização do extrato bruto aquoso (EBA) de gengibre (100 mL.L ${ }^{1}$ de $\left.\mathrm{H}_{2} \mathrm{O}\right)$; (2) aplicação na base de cada planta de $20 \mathrm{~g}$ de massa de gengibre (MG); (3) pulverização com ASM - acibenzolar-S-metil (1 g i.a.100 $\left.\mathrm{L}^{-1} \mathrm{H}_{2} \mathrm{O}\right)$. A aplicação dos tratamentos foi semanal. $\mathrm{Na}$ testemunha absoluta, as plantas foram irrigadas somente com água. Esse procedimento se estendeu até o momento da colheita, sendo avaliados em cada parcela o peso fresco $(\mathrm{g})$, número de folhas e incidência da doença (\%). Para a quantificação da incidência de doença, foi utilizado o método direto expresso em porcentagem de plantas doentes, ou de suas partes na parcela experimental (2). Para o cálculo da produtividade, a massa da matéria fresca, foi expressa em kg.ha-1. O delineamento experimental foi o de blocos inteiramente casualizados, com quatro tratamentos e três repetições. As médias dos tratamentos foram comparadas através do teste de Tukey $(P \mathrm{~d}<0,05)$. 


\section{Mecanismos bioquímicos de resistência}

a) Atividade da peroxidase - Amostras das folhas de alface após a última aplicação dos tratamentos foram colhidas e homogeneizadas em almofariz de porcelana na presença de $4,0 \mathrm{~mL}$ de tampão acetato 100 mM (pH 5,0) (tampão de extração) e posteriormente filtradas em papel Whatman $\mathrm{n}^{\mathrm{o}} 1$. O sobrenadante foi recolhido para avaliação da atividade enzimática.

A atividade das peroxidases foi determinada a $30^{\circ} \mathrm{C}$, por meio de método espectrofotométrico direto (15). A mistura da reação consistiu de $2,9 \mathrm{~mL}$ de uma solução contendo $250 \mu \mathrm{L}$ de guaiacol e $306 \mu \mathrm{L}$ de peróxido de hidrogênio em $100 \mathrm{~mL}$ de tampão fosfato $0,01 \mathrm{M}(\mathrm{pH}$ $6,0)$ e $0,1 \mathrm{~mL}$ de preparação enzimática. A reação foi seguida em espectrofotômetro a $470 \mathrm{~nm}$. Os resultados foram expressos em unidade enzimática (U.E.)/min/mg de proteína.

O teste de Bradford (7) foi empregado para a quantificação do conteúdo total de proteínas. Para tanto, foram adicionados a cada 0,8 $\mathrm{mL}$ de amostra, $0,2 \mathrm{~mL}$ de reagente de Bradford concentrado. Após 5 min, realizou-se a leitura de absorbância a $595 \mathrm{~nm}$.

b) Bioensaios para indução de fitoalexinas em cotilédones de soja - Sementes de soja (Glycine max L. Merrill) cv IAC-8 foram desinfestadas em hipoclorito de sódio (1\%) por 10 min e semeadas em bandejas contendo areia autoclavada. As bandejas foram colocadas em casa de vegetação por 10 dias, sendo em seguida, destacados os cotilédones para realização do bioensaio. Estes foram colocados em placas de Petri (seis cotilédones/placa) contendo três folhas de papel de filtro, esterilizadas e umedecidas com água destilada esterilizada. Em cada cotilédone fez-se um corte em secção aproximada de $1 \mathrm{~mm}$ de espessura e $6 \mathrm{~mm}$ de diâmetro a partir da superfície inferior e, foram adicionados $20 \mu \mathrm{L}$ do EBA nas concentrações anteriormente mencionadas. As placas foram incubadas em BOD, à temperatura de $25^{\circ} \mathrm{C}$ no escuro, por $20 \mathrm{~h}$. Após esse período, os cotilédones foram transferidos para erlenmeyers com $15 \mathrm{~mL}$ de água destilada esterilizada e estes foram colocados sob agitação constante durante $1 \mathrm{~h}$, para a extração dos pigmentos. Em seguida, retiraram-se os cotilédones e o sobrenadante foi lido em espectrofotômetro com absorbância de $285 \mathrm{~nm}$ (3). Como testemunha, utilizou-se água destilada esterilizada.

c) Bioensaios para indução de fitoalexinas em mesocótilos de sorgo - Sementes de sorgo (Sorghum bicolor (L.) Moench) cv. Brandes, foram desinfestadas em hipoclorito de sódio $1 \%$, por $15 \mathrm{~min}$ e lavadas em água destilada. Após esse período, as sementes foram enroladas em folhas de papel de germinação umedecidas com água destilada e incubadas em escuro a $28^{\circ} \mathrm{C}$ por quatro dias. Em seguida, as plântulas formadas foram inicialmente expostas à luz por $4 \mathrm{~h}$ para paralisar a elongação dos mesocótilos. Para o teste de produção de fitoalexinas, os mesocótilos foram excisados $0,5 \mathrm{~cm}$ acima do nó escutelar e colocados em tubos para microcentrífuga (três mesocótilos/tubo), com $1 \mathrm{~mL}$ do EBA (concentrações de 1, 5, 10, 15,20 e $25 \%$ ). Como testemunha, utilizou-se água destilada esterilizada. Os tubos foram mantidos em câmara úmida, a $25^{\circ} \mathrm{C}$, sob luz fluorescente por um período de $60 \mathrm{~h}$. Após esse período, os mesocótilos foram retirados dos tubos, secos e os $5 \mathrm{~mm}$ basais de cada mesocótilo foram excisados e descartados. A porção superior foi pesada, cortada em pequenos segmentos e colocada em novos tubos contendo $1,4 \mathrm{~mL}$ de metanol $80 \%$ acidificado $(0,1 \% \mathrm{HCl}$; v/ v). Os mesocótilos cortados foram mantidos a $4{ }^{\circ} \mathrm{C}$ no metanol por $96 \mathrm{~h}$ para extração dos pigmentos. A absorbância foi determinada a $480 \mathrm{~nm}(18)$.

\section{RESULTADOS E DISCUSSÃO}

\section{Inibição do crescimento micelial e produção de escleródios de $S$. sclerotiorum}

A análise de variância revelou que para as variáveis crescimento micelial e produção de escleródios houve efeito significativo das concentrações do EBA $(P \mathrm{~d}<0,05)$. Através da análise de regressão (Figura 1), verificou-se que, tanto a inibição do crescimento micelial, quanto a produção de escleródios apresentou uma tendência linear crescente em relação às concentrações do EBA.

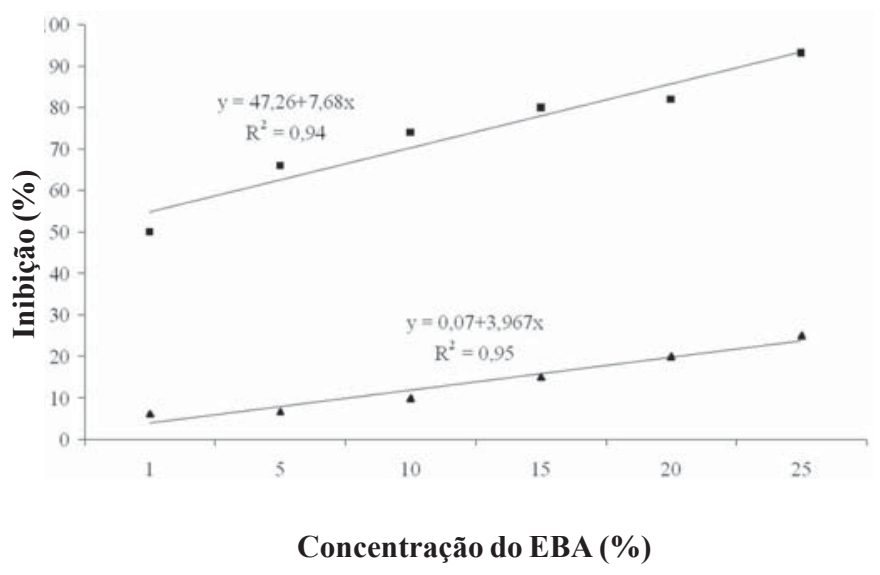

Figura 1. Inibição do crescimento micelial (অ) e da produção de escleródios (ム) de Sclerotinia sclerotiorum em diferentes concentrações do extrato bruto aquoso (EBA) de Zingiber officinalis (gengibre).

Entretanto, foi observado um efeito mais evidente do EBA sobre o crescimento micelial, visto que na mais alta concentração do extrato $(25 \%)$ o crescimento foi inibido em $92,5 \%$ e a inibição da produção de escleródios não alcançou o valor de $30 \%$.

Este efeito antimicrobiano in vitro do gengibre já foi verificado para outros fungos fitopatogênicos. Kane et al. (16) observaram redução de $100 \%$ do crescimento micelial de Rhizoctonia solani quando utilizaram o extrato de gengibre. Tylkowska \& Dorna (25), observaram inibição do crescimento micelial de Alternaria brassicae, Alternaria brassicicola, Botrytis allii e Stemphylium botryosum com o extrato dessa planta.

\section{Controle da podridão de esclerotínia em plantas de alface}

O tratamento com MG (massa de gengibre) foi o mais eficiente para controle, ainda que parcial, do patógeno, proporcionando menor incidência da doença (26\%), quando comparado aos tratamentos ASM (40\%), EBA e água (30\%), sendo estes dois últimos não estatisticamente diferentes $(P \mathrm{~d}<0,05)$ (Figura 2).

Quando analisada a variável peso fresco da planta, observou-se que as alfaces tratadas com MG apresentaram peso médio de 329,3 $\mathrm{g} /$ planta, sendo este valor semelhante ao obtido em alfaces cultivadas no sistema de agricultura convencional ( $340 \mathrm{~g} /$ planta). O número de folhas/planta variou em média de 14,5 a 17,5 . Apenas o tratamento ASM diferiu dos demais, quando submetido ao teste de Tukey $(P \mathrm{~d}<0,05)$, apresentando menor rendimento de folhas, porém com melhor qualidade visual (Tabela 1). Na literatura não há relatos do controle de $S$. sclerotiorum em alface por gengibre. No caso de outros patossistemas, pode-se encontrar o controle de Pyricularia grisea em casa de vegetação pelo extrato de gengibre a $20 \%(21)$. 


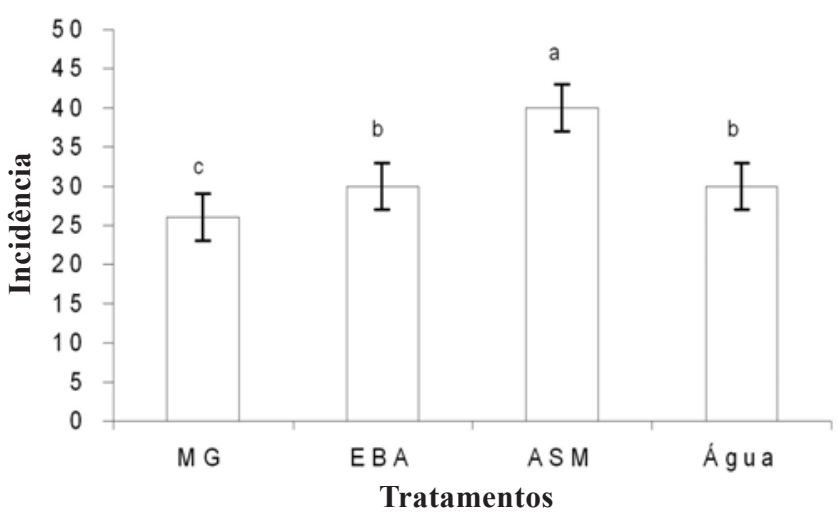

Figura 2. Incidência (\%) de Sclerotinia sclerotiorum em alface após aplicação dos tratamentos massa de Zingiber officinalis (gengibre) (MG), extrato bruto aquoso (EBA) de gengibre a 25\%, acibenzolar-S-metil (ASM) e água. Colunas seguidas de mesma letra não diferem entre si pelo teste de Tukey $(\mathrm{P} \mathrm{d}<0,05)$. As barras representam o erro padrão da média.

Tabela 1. Peso médio ( $\mathrm{g}$ ) de alfaces e número de folhas por planta, após aplicação de massa de Zingiber officinalis (gengibre) (MG), extrato bruto aquoso (EBA) de gengibre a 25\%, acibenzolar-S-metil (ASM) e Água.

\begin{tabular}{ccc}
\hline Tratamentos & Peso médio (g) & $\begin{array}{c}\text { Número de } \\
\text { folhas/ planta }\end{array}$ \\
MG & $329,3 \mathrm{~A}^{*}$ & $17,5 \mathrm{~A}$ \\
EBA & $289,2 \mathrm{~A}$ & $16,6 \mathrm{~A}$ \\
ASM & $241,5 \mathrm{~B}$ & $14,5 \mathrm{~B}$ \\
Água & $286,7 \mathrm{~A}$ & $16,1 \mathrm{~A}$ \\
\hline
\end{tabular}

*Valores seguidos da mesma letra na coluna não diferem entre si pelo teste de Tukey $(\mathrm{P} \mathrm{d}<0,05)$.

\section{Atividade de peroxidases em plantas de alface}

Apesar de não ter diferença estatística entre os tratamentos $(P \mathrm{~d}<0,05)$, a maior atividade de peroxidase ocorreu no tratamento com MG. Nos tratamentos com EBA e água, a atividade enzimática foi de 2,45 e 2,15 U.E./min/mg proteína, respectivamente, tendo o ASM proporcionado a menor atividade da enzima, quando comparado aos demais tratamentos (Figura 3). Estes resultados com ASM são

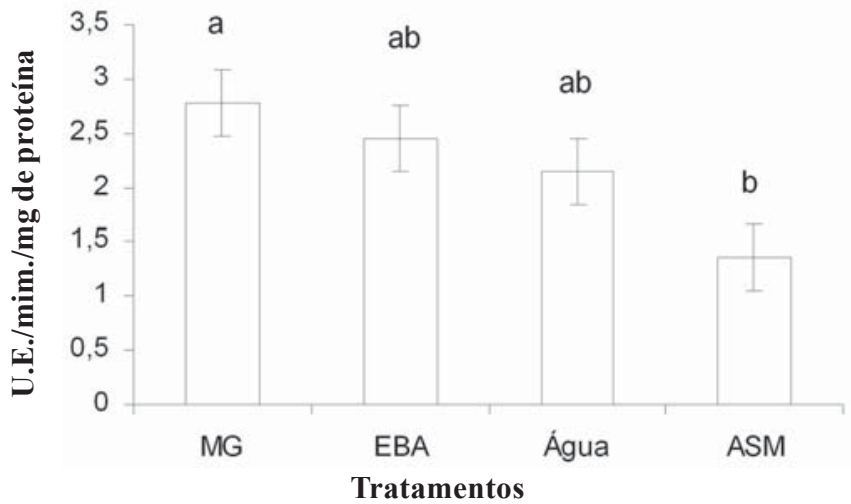

Figura 3. Atividade específica (U.E./min/mg de proteína) da enzima peroxidase em folhas de Lactuca sativa tratadas com massa de Zingiber officinalis (gengibre) (MG), extrato bruto aquoso (EBA) de gengibre a $25 \%$, acibenzolar-S-metil (ASM) e água. Colunas seguidas da mesma letra não diferem entre si pelo teste de Tukey $(P \mathrm{~d}<0,05)$. As barras representam o erro padrão da média. contrários aos relatados por Rezende et al (22) para o patossistema cacau-Verticillium dahliae onde observaram aumento na atividade da enzima peroxidase considerando-a importante na indução sistêmica em cacaueiro.

A indução da atividade de peroxidase tem sido verificada em outros patossistemas quando se testam compostos naturais para o controle de doenças. Ao utilizar extratos do cogumelo shiitake (Lentinula edodes) no patossistema pepino x Colletotrichum lagenarium, Di Piero \& Pascholati (12) verificaram elevação na síntese de proteínas relacionadas à patogênese (quitinases e peroxidases), dando uma indicação de que compostos do cogumelo poderiam estar atuando sobre o hospedeiro e contribuindo para a redução da severidade da doença. Por outro lado, Fiori-Tutida (13) verificou que os extratos brutos dos cogumelos L. edodes e Agaricus blazei, na concentração de 40.000 ppm, pré-aplicados em mesocótilos de trigo, não foram capazes de reduzir a severidade da doença causada por B. sorokiniana, apesar de possuírem atividade eliciadora de peroxidase e glucanase.

No presente trabalho verificou-se uma relação entre ativação de peroxidases e indução de resistência, visto que o tratamento com $\mathrm{MG}$, além de proporcionar maior controle da doença (Figura 2), ocasionou aumento na atividade desta enzima nos tecidos das plantas de alface. As peroxidases participam do processo de lignificação de células vegetais, sendo necessárias para a polimerização final de compostos fenólicos junto à lignina. Esta última por sua vez pode afetar o desenvolvimento fúngico, seja através de bloqueio físico, tornando as paredes celulares mais resistentes à penetração mecânica, seja pela redução da difusão de nutrientes para o fungo, bem como de toxinas e enzimas fúngicas para a planta. Embora se tenha observado uma proteção parcial das plantas de alface contra $S$. sclerotiorum, não foi verificado efeito sistêmico do agente protetor (MG), uma vez que não houve diferença estatística significativa entre os tipos de folhas testadas (basais e novas) (dados não mostrados).

\section{Indução de fitoalexinas}

Verificou-se que o EBA de gengibre, nas diferentes concentrações, apresentou comportamento diferenciado em relação às capacidades de indução de fitoalexinas 3-deoxiantocianidinas e gliceolina, para as quais foram ajustadas curvas lineares e quadráticas, respectivamente (Figura 4).

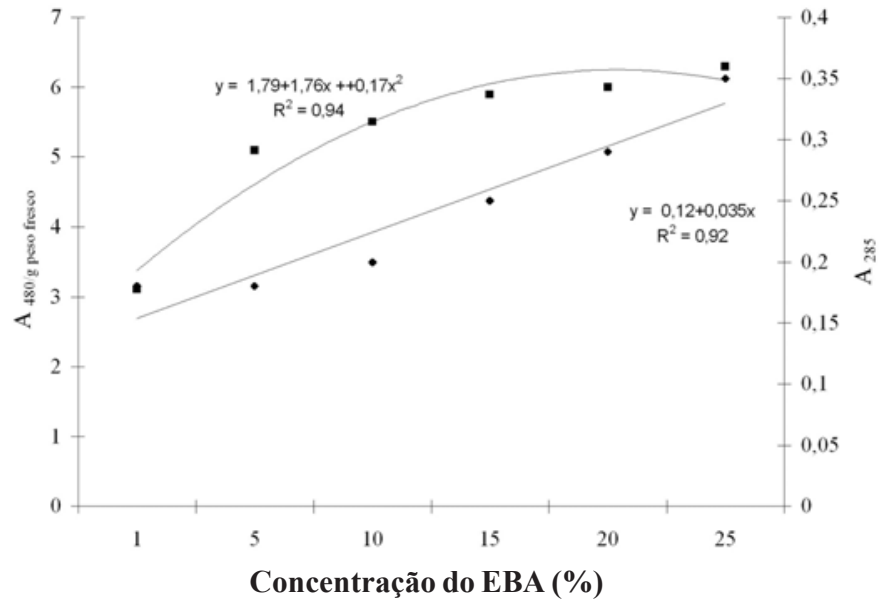

Figura 4. Acúmulo de fitoalexinas em mesocótilos de sorgo ( (absorbância a $480 \mathrm{~nm} /$ grama de peso fresco) e cotilédones de soja (•) (absorbância a $285 \mathrm{~nm}$ ) após tratamento com extrato bruto aquoso (EBA) de Zingiber officinalis (gengibre). 
Stangarlin et al. (24) avaliaram a produção de fitoalexinas em mesocótilos de sorgo e cotilédones de soja quando aplicados diferentes extratos de plantas e observaram que extratos de romã, erva cidreira, manjerona, babosa e orégano foram eficientes na indução de fitoalexinas 3-deoxiantocianidinas em sorgo, enquanto que os extratos de pitanga, cânfora, poejo, romã e cardo santo proporcionaram o acúmulo de gliceolinas em soja. Colpas (10) verificou que o extrato aquoso de Ocimum gratissimum (alfavaca-cravo), na concentração de $30 \%$, induziu a produção de gliceolina em cotilédones de soja e de 3deoxiantocianidinas em mesocótilos de sorgo.

$\mathrm{O}$ efeito elicitor de fitoalexinas verificado nos bioensaios com sorgo e soja indica que o extrato bruto aquoso de gengibre possui a capacidade de ativar mecanismos de defesa nessas plantas.

Estes resultados indicam o potencial de Z. officinalis para o controle de $S$. sclerotiorum em alface, o qual pode ocorrer tanto por atividade antimicrobiana direta quanto pela ativação de mecanismos de defesa. Entretanto estudos adicionais devem ser conduzidos visando possibilitar a recomendação prática de uso de massa de gengibre no colo da plantas para o controle da murcha de esclerotínia em cultivos agroecológicos.

\section{REFERÊNCIAS BIBLIOGRÁFICAS}

1. Albuquerque, J.M. Plantas medicinais de uso popular. Brasília: ABEAS/MEC, 1989; 96p.

2. Amorin, L. Sobrevivência do inóculo. In: Bergamin Filho, A.; Kimati, H.; Amorin, L. Manual de Fitopatologia: princípios e conceitos. São Paulo: Ed Agronômica Ceres, 1995. v.1, cap.13, p. 246-267.

3. AYERS, A.R.; EBE, J.; FINELLI, F.; BERGER, N.; ALBERSHEIM, P.; Host-pathogen interactions. IX. Quantitative assays of elicitor activity and characterization of the elicitor present in the extracellular medium of cultures of Phytophthora megasperma var. sojae. Plant Physiology, v.57, p.751-759, 1976a

4. Balbi-Peña, M.I. Efeito do extrato do rizoma de Curcuma longa e solução de curcumina em Alternaria solani e controle da pinta preta em tomateiro. 2005. 50f. Dissertação (Mestrado em Agronomia) - Universidade Estadual do Oeste do Paraná, Marechal Cândido Rondon.

5. Becker, A.; Vigo-Schultz, S.C.; Stangarlin, J.R.; Balbi-Peña, M.I., Klahold, C.A.; Schwan-Estrada, K.R.F. Controle alternativo das doenças de final de ciclo e oídio na cultura da soja. Fitopatologia Brasileira, Brasília, v.29, supl., p.163-163, 2004. (Resumo).

6. Bonaldo, S.M.; Schwan-Estrada, K.R.F.; Stangarlin, J.F.; Tessmann, D J.; Scapim, C.A. Fungitoxicidade, atividade elicitora de fitoalexinas e proteção de pepino contra Colletotrichum lagenarium, pelo extrato aquoso de Eucalyptus citriodora. Fitopatologia Brasileira, Brasília, v.29, n.2, p.128-134, 2004.

7. Bradford, M. A rapid and sensitive method for the quantitation microgram quantities of protein utilizing the principle of protein-dye binding. Analytical Biochemistry, Bethesda, v.72, p.248-254, 1976.

8. CEASA-PARANÁ. Disponível em: < www.ceasa.paraná > Acesso em: 30/04/2004.

9. Carneiro, S.M.T.P.G. Efeito de extratos de folhas e do óleo de nim sobre o oídio do tomateiro. Summa Phytopathologica, Botucatu, v.29, n.3, p.262-265, 2003.

10. Colpas, F.T. Atividade eliciadora de extratos de alfavaca-cravo (Ocimum gratissimum L.). 2002. 63f. Dissertação (Mestrado em
Proteção de Plantas) - Universidade Estadual de Maringá, Maringá. 11. Dhingra, O.D.; Costa, M.L.N.; Silva Jr., G.J.; Mizubuti, S.G. Essential oil of mustard to control Rhizoctonia solani causing seedling damping off and seedling blight in nursery. Fitopatologia Brasileira, Brasília, v.29, n.6, p.683-686, 2004.

12. Di Piero, R.M.; Pascholati, S.F. Indução de resistência em plantas de pepino contra Colletotrichum lagenarium pela aplicação de extratos de basidiocarpos de Lentinula edodes e de Agaricus blazei. Summa Phytopathologica, Botucatu, v.30, n.2, p.243-250, 2004.

13. Fiori-Tutida, A.C.G. Uso de extratos de cogumelos comestíveis e medicinais no controle da ferrugem da folha e helmintosporiose em trigo. 2003. 118f. Tese (Doutorado em Proteção de Plantas) - Universidade Estadual de Maringá, Maringá.

14. Franzener, G.; Stangarlin, J.R.; Schwan-Estrada, K.R.F.; Cruz, M.E.S. Atividade antifúngica e indução de resistência em trigo a Bipolaris sorokiniana por Artemisia camphorata. Acta Scientiarum, Maringá, v.25, n.2, p.503-507, 2003.

15. Hammerschmidt, T.R.; Nucles, E.M.; Kuc, J. Association of enhance peroxidase activity with induced systemic resistance of cucumber to Colletotrichum lagenarium. Physiological Plant Pathology, Fasialabad, v.20, p.73-82, 1982.

16. Kane, P.V.; Kshisargar, C.R.; Jadhav, A.C.; Pawar, N.B. In vitro evaluation of some plant extracts against Rhizoctonia solani from chickpea. Journal of Maharashtra Agricultural Universities, Pune, v.27, n.1, p.101-102, 2002.

17. Kuhn, O.J.; Portz, R. L.; Stangarlin, J. R.; Del Águila, R. M.; Schwan-Estrada, K. R. F.; Franzener, G. Efeito do extrato aquoso de cúrcuma (Curcuma longa) em Xanthomonas axonopodis pv. manihotis. Semina: Ciências Agrárias, Londrina, v.27, n.1, p. 13-20, 2006.

18. Nicholson, R.L.; Kollipara, S.S.; Vincent, J.R.; Lyons, P.C.; Cadena-Gomez, G. Phytoalexin synthesis by the sorghum mesocotyl in response to infection by pathogenic and nonpathogenic fungi. Proceedings of the National Academy Science, USA, v.84, p.5520-5524, 1987.

19. Pandey, M.K.; Singh, A.K.; Singh, R.B. Mycotoxic potential of some higher plants. Plant Disease Research, St. Paul, v.17, n. 1, p.51-56, 2002.

20. Pavan, M.A.; Kurozawa, C. Doenças da alface (Lactuca sativa). Kimati, H.; Amorin, L.; Bergamin Filho, A.; Camargo, L.E.A.; Rezende, J.A.M. Manual de fitopatologia: doenças das plantas cultivadas. São Paulo: Ed Agronômica Ceres, 1997. v.2, cap. 4, p. $18-25$

21. Prasad, M.S.; Prasad, M.S.L.; Sharma, Y.P. Fungitoxicity of plant products against Pyricularia grisea. Annals of Plant Protection Sciences, New Delhi, v.10, n.2, p.388-390, 2002.

22. Resende, M.L.V.; Nojosa, G.B.A.; Cavalcanti, L.S.; Aguilar, M.A.G.; Silva, L.H.C.P.; Perez, J.O.; Andrade, G.C.G.; Carvalho, G.A.; Castro, R.M. Induction of resistance in cocoa against $\mathrm{Cri}$ nipellis perniciosa and Verticillium dahliae by acibenzolar-S-methyl (ASM). Plant Pathology, St. Paul, v.5, p.261-268, 2002

23. Schwan-Estrada, K.R.F.; Stangarlin, J.R.; Cruz, M.E.S. Uso de plantas medicinais no controle de doenças de plantas. Fitopatologia Brasileira, Brasília, v.28, p.554-556, 2003.

24. Stangarlin, J.R.; Schwan-Estrada, K.R.F.; Cruz,M.E.S.; Nozaki, M.H. Plantas medicinais e o controle alternativo de doenças de plantas. Biotecnologia Ciência \& Desenvolvimento, Brasília, v.11, p.16-21, 1999.

25. Tylkowska, K.; Dorna, H. Effects of cinnamon, garlic, greater celandine, ginger and chosen fungicides on the growth of pathogenic fungi isolated from onion, cabbage and carrot seeds. Phytopathologia Polonica, Skierniewice, n.21, p.25-34, 2001. 